\title{
Where's Icarus? Stigma based on weight that no one wants to see. A candid answer to "A candid discussion of obesity"
}

\author{
Daniele Di Pauli ${ }^{1}$
}

Received: 10 May 2016/Accepted: 18 May 2016/Published online: 7 June 2016

(C) Springer International Publishing Switzerland 2016

The editorial written by Robert Doroghazi "A Candid Discussion of Obesity," published in March 2015 in the journal "The American Journal of Medicine" deserves a response that has been shared by the Italian Society for the Study of Eating Disorders (SISDCA), the Italian Obesity Society (SIO), and the Association Diamole Peso Onlus.

Doroghazi describes obesity as a personal choice and writes that there will be no progress in the fight against this public health problem, unless we tell patients who eat too much and that it's their own responsibility to eat less.

In fact, the author suggests to tell patients that it is not okay to be obese and that their obesity cannot be blamed on the fast food or carbonated beverage industry or on anyone or anything else, because it is their fault if they weigh so much, and that weight and health are their responsibility [1].

The words of Doroghazi represent perfectly one of the most disabling and less considered aspects of obesity: the stigma against this condition and those affected [2].

In this perspective, the excess of weight is not considered an illness but a guilt, and, the body, both for adults and children, becomes the target for teasing, negative judgments, stereotypes, and penalties in the most important domains of life, such as work, education, mass media, social media, interpersonal relationships, and leisure time [3].

Even the healthcare environment is not immune to these negative attitudes that have been detected in doctors, nurses, gynecologists, psychologists, dieticians, medical students, and finally, also in a number of professionals

\footnotetext{
Daniele Di Pauli

danieledipauli@hotmail.com

1 Rovereto, Italy
}

dedicated to the treatment of obesity and eating disorders (ED) [4-7].

The patient with obesity is described by health professionals, as not intelligent, uncooperative, not adhering to the recommendations provided, and with no will power $[6,8,9]$.

The perception of a guilt-inducing environment can lead the person with obesity to avoid treatment or delete important preventive examinations with the risk of maintaining and/or worsening their condition over time [3].

Not only there is a problem with attitudes, but sometimes, even the environment is not suitable for the needs of people with obesity (e.g., narrow armchairs, medical instrumentation that doesn't fit, scales located in places where there is no privacy), and this can discourage a call for help [10, 11].

Doroghazi seems not to consider the multifactorial nature of obesity and the complex biological and psychological mechanisms that are activated in response to attempts to reduce weight and that in 2011, the American Association of Clinical Endocrinologists (AACE) and, in 2013, the American Medical Association (AMA) officially declared that obesity is a disease and requires treatment [12, 13]. Also, according to the guidelines released by the American Heart Association (AHA), American College of Cardiology, and The Obesity Society, doctors should consider obesity a disease and treat obese patients for weight loss [14]. However, a new commonly established characterization and classification of obesities based on a number of variables and not only on BMI is needed urgently [15].

Obesity is not a choice, or the result of little self-care and being greedy, but a chronic disease [16].

To cure it, we must not forget the respect of the person that is made of rapport, environment/equipment, safety, privacy, encouragement, care/compassion, and tact [17]. 
The same respect that Albert Stunkard called "golden opportunity" and "the greatest gift that a doctor can give to a patient with obesity" [18].

As health professionals, and scientific societies, we cannot allow the stigma toward obesity to go unnoticed like happens to Icarus, in the painting by Pieter Bruegel the Elder, in which no one seems to notice the son of Daedalus fallen from the sky into the sea.

In this painting, even if it is happening as an event of exceptional importance, life seems to go on as if nothing had happened, and even those who admire the picture for the first time barely notice the legs of the young man out of the water at the bottom right of the painting.
The stigma based on weight even if it is always more pervasive, common, and under everybody's eyes [19] is like Icarus represented by Bruegel "no one seems to see it or give importance."

In conclusion, I would suggest telling patients, "Sir or Madam, obesity is not a choice or a fault, but a chronic disease that can have negative effects on physical and mental health. The environment in which we live, and our biology are powerful obstacles, but we can learn to recognize and manage them. It will not be always easy, but we will learn that the difficulties can become opportunities. We must begin with mutual respect, this is the first step... this is our responsibility".

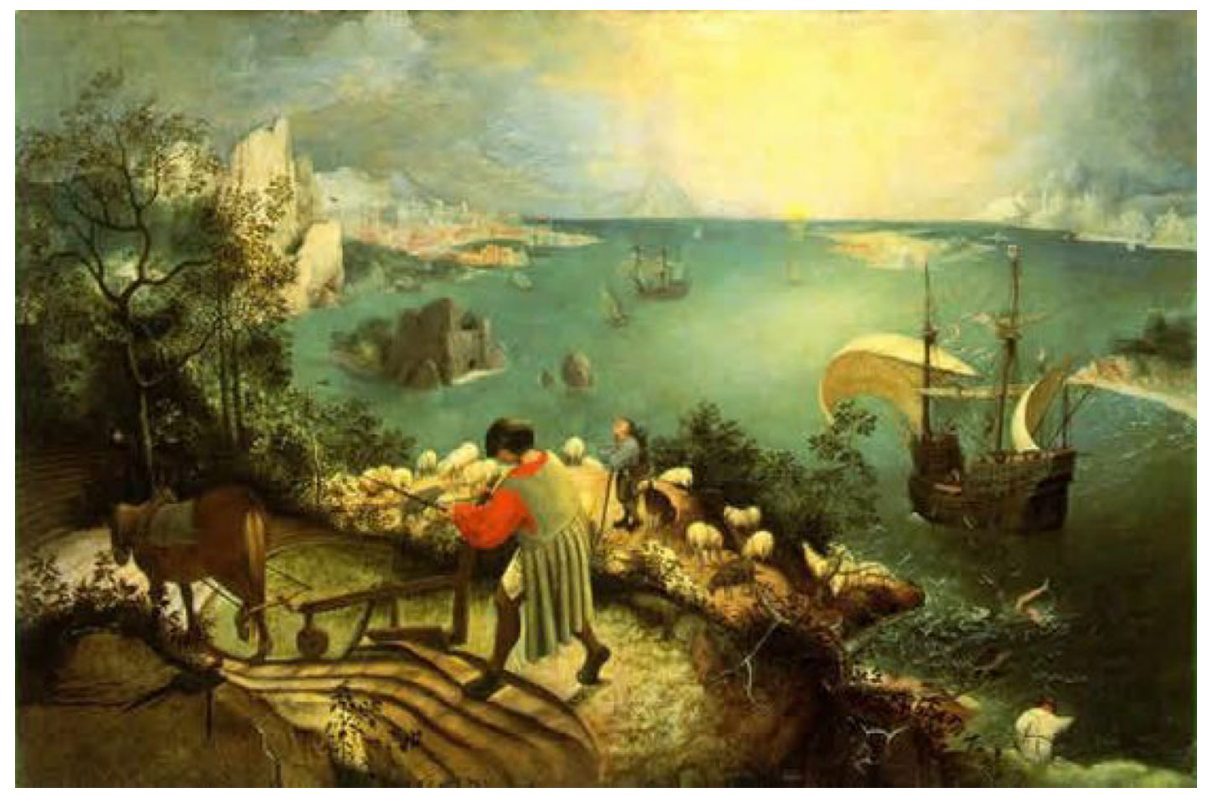

"Landscape with the fall of Icarus" P. Bruegel the Elder, Museum van Buuren, Brussels, Belgium.

\section{Compliance with ethical standards}

Funding No funding.

Conflict of interest The Author declares that he has no conflict of interest.

Ethical approval This article does not contain any studies with human participants or animals performed by the author.

\section{References}

1. Doroghazi RM (2015) A candid discussion of obesity. Am J Med 128(3):213-214. doi:10.1016/j.amjmed.2014.09.024

2. Technical report: From weight to well being. Time for a shift in paradigm? http://www.phsa.ca/population-public-health-site/ Documents/W2WBTechnicalReport_20130208FINAL.pdf
3. Puhl RM, Heuer CA (2009) The stigma of obesity: a review and update. Obesity (Silver Spring) 17(5):941-964. doi:10.1038/oby. 2008.636

4. Phelan SM, Burgess DJ, Yeazel MW, Hellerstedt WL, Griffin JM, van Ryn M (2015) Impact of weight bias and stigma on quality of care and outcomes for patients with obesity. Obes Rev 16(4):319-326. doi:10.1111/obr.12266

5. Phelan SM, Dovidio JF, Puhl RM, Burgess DJ, Nelson DB, Yeazel MW, Hardeman R, Perry S, van Ryn M (2014) Implicit and explicit weight bias in a national sample of 4732 medical students: the medical student CHANGES study. Obesity (Silver Spring) 22(4):1201-1208. doi:10.1002/oby.20687

6. Schwartz MB, Chambliss HO, Brownell KD, Blair SN, Billington C (2003) Weight bias among health professionals specializing in obesity. Obes Res 11(9):1033-1039. doi:10.1038/oby.2003.142

7. Puhl RM, Latner JD, King KM, Luedicke J (2014) Weight bias among professionals treating eating disorders: attitudes about treatment and perceived patient outcomes. Int J Eat Disord 47(1):65-75. doi:10.1002/eat.22186

8. Hebl MR, Mannix LM (2003) The weight of obesity in evaluating others: a mere proximity effect. Pers Soc Psychol Bull 29(1):28-38. doi:10.1177/0146167202238369 
9. Persky S, Eccleston CP (2011) Impact of genetic causal information on medical students' clinical encounters with an obese virtual patient: health promotion and social stigma. Ann Behav Med 41(3):363-372. doi:10.1007/s12160-010-9242-0

10. Kaminsky J, Gadaleta D (2002) A study of discrimination within the medical community as viewed by obese patients. Obes Surg 12(1):14-18. doi:10.1381/096089202321144513

11. Merrill E, Grassley J (2008) Women's stories of their experiences as overweight patients. J Adv Nurs 64(2):139-146. doi:10.1111/j. 1365-2648.2008.04794.x

12. American Association of Clinical Endocrinologists (AACE) (2011) American Association of Clinical Endocrinologists (AACE) declares obesity a disease state. http://media.aace.com/ press-release/american-association-clinical-endocrinologistsaacedeclares-obesity-disease-state. Accessed 11 Nov 2014

13. American Medical Association House of Delegates (2013) Report of the Council on Science and Public Health (CSAPH), Recognition of obesity as a disease. Resolution 420 (A-13), p 19. http:// www.ama-assn.org/assets/meeting/2013a/a13-addendum-refcommd.pdf. Accessed 11 Nov 2014

14. Jensen MD, Ryan DH, Apovian CM, Ard JD, Comuzzie AG, Donato KA, Hu FB, Hubbard VS, Jakicic JM, Kushner RF, Loria
CM, Millen BE, Nonas CA, Pi-Sunyer FX, Stevens J, Stevens VJ, Wadden TA, Wolfe BM, Yanovski SZ (2013) 2013 AHA/ACC/ TOS Guideline for the management of overweight and obesity in adults: a report of the American College of Cardiology/American Heart Association Task Force on practice guidelines and The Obesity Society. Circulation. doi:10.1161/01.cir.0000437739. 71477.ee

15. Bosello O, Donataccio MP, Cuzzolaro M (2016) Obesity or obesities? Controversies on the association between body mass index and premature mortality. Eat Weight Disord 21(2):165174. doi:10.1007/s40519-016-0278-4

16. Sharma AM (2009) Obesity is not a choice. Obes Rev 10(4):371-372. doi:10.1111/j.1467-789X.2009.00619.x

17. Susan M (2008) Bejciy-spring, R-E-S-P-E-C-T: a model for the sensitive treatment of the bariatric patient. Bariatr Nurs Surg Patient Care 3(1):47-56. doi:10.1089/bar.2008.9991

18. Stunkard A (1993) From, "talking with patients", obesity: theory and therapy. Raven Press, New York

19. Andreyeva T, Puhl RM, Brownell KD (2008) Changes in perceived weight discrimination among Americans, 1995-1996 through 2004-2006. Obesity 16(5):1129-1134. doi:10.1038/oby. 2008.35 